\title{
USO DA TECNOLOGIA NO CURSO DE PEDAGOGIA DA UNIVERSIDADE ESTADUAL DE FEIRA DE SANTANA
}

\section{Maísa Lis C. dos Santos ${ }^{1}$; Solange Mary Moreira Santos ${ }^{2}$; Monique Santos Santana. ${ }^{3}$}

1. Bolsista PIBIC/CNPq, Graduando em Licenciatura em Pedagogia, Universidade Estadual de Feira de Santana, e-mail: maiisacliis@hotmail.com

2. Orientador, Departamento de Educação, Universidade Estadual de Feira de Santana, e-mail: solangemmsantos@gmail.com 3. Participante do projeto ou núcleo de estudo e pesquisa sobre formação de professor-NUFOP, Departamento de Educação, Universidade Estadual de Feira de Santana, e-mail: monisks@hotmail.com

\section{PALAVRAS-CHAVE: Formação; Tecnologia; Pedagogia.}

\section{INTRODUÇÃO}

As Tecnologias de Informação e Comunicação (TICs) têm ganhado seu espaço na sociedade, desenvolvendo formas diferentes de armazenar, recuperar e, principalmente, disseminar o conhecimento. Atualmente, o acesso ao conhecimento e à informação acontece mais rapidamente e as novas gerações têm mais acesso que as anteriores, pois as crianças e os jovens convivem em um cenário onde os recursos tecnológicos apresentam um repertório de referências relativas às atividades de lazer, de estudos, de contato, dentre outras funções. $\mathrm{O}$ autor Moran, (2000, p.11) nos diz que, "todos estamos experimentando que a sociedade está mudando nas suas formas de organizar-se, de produzir bens, de comercializa-los, de divertirse, de ensinar e de aprender".

Com o crescimento das TIC's no meio social, a internet também ganha espaço na sociedade, modificando consideravelmente na área cultural, familiar e científica. Dessa forma, em todas as áreas da vida humana existe uma notável e rápida modificação nos modos de ser e agir do indivíduo. $\mathrm{O}$ uso da internet se dá por uma exigência da cibercultura, que produz transformações na vivência dos indivíduos, em seu cotidiano, nas práticas sociais e na forma de produção e consumo de informações, que com a popularização da internet aconteceu de forma mais rápida e dinâmica através do ciberespaço.

Com a internet e as redes de comunicação, surgem novos espaços importantes para o processo ensino-aprendizagem, que modificam e ampliam as atitudes convencionais na sala de aula. É nesse sentido que o surgimento da internet influência no meio educacional, pois, acredita que as TICs trariam soluções rápidas para a educação.

Dessa forma, há uma necessidade de rever as práticas pedagógicas presentes no cotidiano escolar, estabelecendo novos parâmetros para inserir de forma efetiva as tecnologias disponíveis, com o intuito de auxiliar tanto alunos quanto professores em seus processos de formação. Os alunos e os professores precisam se adequar para acompanhar esse movimento tecnológico dos últimos tempos, implicando em se repensar o papel dos espaços formativos e do professor diante dessa nova demanda social. Nesta seção, apresentamos uma breve discussão sobre a inserção das TICs no processo de formação do estudante de Pedagogia, mais especificamente no curso de Pedagogia da Universidade Estadual de Feira de SantanaUEFS.

Assim, diante do exposto, essa investigação tem a pretensão de responder a seguinte questão: Como acontece a interação entre os docentes e discentes através dos recursos tecnológicos como internet, facebook, e-mails, whatsapp entre outros? A utilização dessas ferramentas tecnológicas contribui para a reflexão dos conteúdos? Qual a percepção dos alunos do curso de Pedagogia sobre o uso das TICs na sala de aula? Este trabalho tem como relevância proporcionar aos professores a compreensão sobre a necessidade da utilização das TIC's nessa formação, ressaltando que a finalidade é a inserção de novas tecnologias na 
mediação com o conhecimento de modo contínuo, bem como sua ampliação para o espaço da aula.

\section{MATERIAL E MÉTODOS OU METODOLOGIA (ou equivalente)}

Levando em consideração os objetivos estabelecidos neste estudo, acreditamos que esta pesquisa está norteada na proposta metodológica situada em uma abordagem qualitativa que "tem preocupação maior com o processo do que com o produto" (ANDRÉ e LUDKE, 1986, p 44). Ainda a esse respeito, Godoy ressalta que a abordagem qualitativa tem "como preocupação fundamental o estudo e a análise do mundo empírico em seu ambiente natural. Nessa abordagem valoriza-se o contato direto e prolongado do pesquisador com o ambiente e a situação que está sendo estudada" (GODOY, 1995 p. 62). Diante disso foi possível até aqui realizar um estudo bibliográfico sobre autores que discutam a inserção das tecnologias dentro do contexto de formação de professores, o que deu sustentação a pesquisa de campo, propiciando assim, um embasamento teórico capaz de colaborar na busca de outras possibilidades e respostas.

Para Marconi e Lakatos (2010), a pesquisa de campo consiste na observação de fatos e fenômenos tal como ocorrem espontaneamente, na coleta de dados a eles referentes e no registro de fatos que se presume relevante, para analisá-los. Essa modalidade de pesquisa é também utilizada para a coleta de informações ou conhecimentos acerca de um problema.

Desse modo, está pesquisa foi desenvolvida com estudantes do curso de Licenciatura em Pedagogia da UEFS, do quarto e sétimo semestre, sendo 4 alunos de cada semestre. A escolha por alunos do quarto semestre partiu primeiramente pelo fato desses estudantes já terem cursado a disciplina Novas Tecnologias de Comunicação e Informação e por já estarem na metade do curso. Já a escolha dos alunos do sétimo se deu pelo fato desses estudantes já terem uma experiência maior com a universidade, pois se encontram no penúltimo semestre do curso e podem relatar com mais propriedade suas experiências durante a trajetória acadêmica frente ao tema pesquisado.

Nesta perspectiva a relevância desta investigação estar em proporcionar aos estudantes da área de educação a reflexão de como foi utilizado ao longo do curso de Pedagogia da UEFS as TICs, como: facebook, whatsapp, e-mails entre outros, e como se estabelece a relação entre ensino-aprendizagem bem como proporcionar a possibilidade de mediação no processo de formação dos graduandos não somente para sua vida acadêmica e profissional, mas também para sua formação como ser humano. Vale ressaltar a necessidade de o educador ter domínio dos recursos tecnológicos buscando adequá-las às ações pedagógicas, utilizando esses recursos para a melhoria da comunicação e colaboração entre os atores educacionais tornando assim o processo educacional dinâmico e interativo.

\section{RESULTADOS E/OU DISCUSSÃO (ou Análise e discussão dos resultados)}

A educação atual está voltada a atender uma demanda da sociedade da informação e comunicação, porém, ela encontra-se obsoleta, em muitos casos é possível ver nesses espaços educativos a presença das TICs, mas essas não são inseridas de forma a colaborar no processo de desenvolvimento dos sujeitos. Em contrapartida há espaços que nem mesmo tem acesso a todo esse aparato tecnológico disponível nos dias atuais, o que se configura um retrocesso quando tratamos de uma sociedade que está envolvida cada vez mais em meio às tecnologias.

$\mathrm{O}$ avanço tecnológico tem provocado o debate sobre o uso dessas ferramentas nas ações pedagógicas, nesse sentido, é necessário discutir aspectos que envolvam a formação do professor e seu papel, bem como os benefícios dessas tecnologias no ato de ensinar e aprender, nos espaços escolares e nos cursos formativos. Com a inserção no ambiente escolar 
de novas fontes de informação, novas tarefas são incorporadas ao trabalho docente. Para Moran (2000):

Um dos grandes desafios para o educador é ajudar a tornar a informação significativa, a escolher as informações verdadeiramente importantes entre tantas possibilidades, a compreendê-las de forma cada vez mais abrangente e profunda e a torná-las parte do nosso referencial. (p.23)

Então, o professor precisa ter uma formação adequada, para que assim possa trabalhar com a inserção dessas tecnologias e os desafios que elas propõem. De acordo com Masetto (2000, p 139) "Não é a tecnologia que vai resolver ou solucionar o problema educacional do Brasil. Poderá colaborar, no entanto, se for usada adequadamente, para o desenvolvimento educacional de nossos estudantes". A formação do professor, desse modo, deve subsidiar aprendizagens que os ajude a inserir as TICs em sua práxis, colaborando com a formação de seus alunos como sujeitos críticos e reflexivos diante dessa nova conjuntura social, de uma sociedade permeada pelo uso das tecnologias.

$\mathrm{Na}$ coleta de dados, extraída do questionário obtivemos algumas respostas que contribuíram para compreender alguns aspectos envolvendo a formação dos pedagogos frente às tecnologias de comunicação e informação.

Nas respostas do questionário aparece que, as TICs se tornam uma grande aliada no processo de formação desses alunos, é importante que essa prática permaneça durante toda sua formação, privilegiando as relações entre pedagogia e tecnologia e tornando significativo no desenvolvimento de atividades com mais qualidade. De acordo com Silva, (2004, p. 7), "[...] a organização da informação diferente da tradicional revela uma consciência de necessidade de mudança e atualização de métodos e práticas pedagógicas". Nesse sentido, o uso das tecnologias nas práticas educativas revela uma mudança no trabalho pedagógico, passando dos métodos tradicionais para métodos mais modernizados com o auxílio das TICs.

Observar-se nos depoimentos, que os estudantes concordam que a Universidade Estadual de Feira de Santana deixa a desejar na infraestrutura principalmente, quando se trata das ferramentas tecnológicos. Dentro de um espaço acadêmico a qualificação teórica é de fundamental importância, no entanto, com o avanço tecnológico acelerado é relevante integrar as TICs no processo de formação inicial dos futuros professores, para que estejam preparados para utilização desses meios.

Percebe-se nas falas dos estudantes que a maioria dos docentes da universidade não tem uma formação adequada para trabalhar com as tecnologias, o que fragiliza suas atuações com os discentes que muitas vezes já estão um pouco mais familiarizados com estes recursos tecnológicos.

Diante do exposto se evidencia que a tecnologia é um grande aliado na vida cotidiana das pessoas. Então como assevera Oliveira (2015), as TICs por si só não fizeram e nem farão uma mudança no processo de ensino aprendizagem sem que haja a intervenção dos sujeitos, isto porque as TICs devem ser vistas como aliado nesse processo e não ser considerada a solução para todos os déficits até hoje apontados nos espaços formativos, quando falamos de ensino-aprendizagem.

\section{CONSIDERAÇÕES FINAIS (ou Conclusão)}


Diante do estudo da literatura e dos depoimentos dos estudantes do curso de Pedagogia da UEFS, ficou evidente que a Universidade precisa de uma reformulação nas suas práticas quanto ao uso das tecnologias. Quando se trata da utilização das ferramentas tecnológicas como suporte para a reflexão dos conteúdos fica claro nos depoimentos a grande contribuição das TICs para a compreensão dos mesmos.

De acordo com os resultados apresentados nesta pesquisa, podemos cogitar que apesar de estarmos cada vez mais conectados, poucas mudanças têm se notado no campo educacional. Os modos de ensinar e aprender não evoluíram na mesma proporção, pois mesmo com a presença das TICs no cotidiano das pessoas, a educação se torna muitas vezes fragilizada com relação a utilização desses meios nos espaços de formação, tanto das escolas básicas quanto nos cursos de formação de professores.

É de grande relevância pensar a tecnologia como um instrumento que pode colaborar na formação e aprendizagem dos sujeitos, porém é preciso ter cautela quanto ao uso destituído de reflexão crítica, pois são apenas ferramentas que se moldam a realidade apresentada. $\mathrm{O}$ professor deverá está atento as novas necessidades, a fim de contribuir de forma eficaz na construção de cidadãos críticos e reflexivos.

\section{REFERÊNCIAS:}

ANDRÉ, Marlir, LUDKE, Menga. Pesquisa em Educação: abordagens qualitativas. São Paulo: EPU 1986.

GODOY, Arllda Schmidt .Introdução à pesquisa qualitativa e suas possibilidades 1995 .

MARCONI, Marina de Andrade; LAKATOS, Eva Maria. Fundamentos de metodologia científica. 7ed. São Paulo: Atlas, 2010.

MASETTO, Marcos Tarciso. Mediação pedagógica e o uso da tecnologia. In: MORAN, José Manuel; MASETTO, Marcos Tarciso; BEHRENS, Marilda Aparecida. Novas tecnologias e mediação pedagógica. Campinas: Papirus, 2000.

MORAN, José Manuel. MASETTO, Marilda, BEHRENS, Aparecida. Novas Tecnologias e Mediação Pedagógica. Campinas, SP: Papirus, 2000.

SILVA, Álvaro António Teixeira Da. Ensinar e aprender com as Tecnologias - Um estudo sobre as atitudes, formação, condições de equipamento e utilização nas escolas do $1^{\circ}$ Ciclo do Ensino Básico do Concelho de Cabeceiras de Basto. 2004. 262 f. Dissertação (Mestrado) Universidade do Minho, Braga, 2004.

OLIVEIRA, Agenor Virgínio. Construção de Ambientes Virtuais de Aprendizagem Baseados na Internet - Utilizando Recursos Gratuitos. Dissertação de Mestrado. Florianópolis : Universidade Federal de Santa Catarina, 2001.

OLIVEIRA, Valéria Alves de.Tecnologias da Informação e Comunicação: Um estudo qualitativo com docentes do curso de Pedagogia. dissertação .Curitiba 2015. 